\title{
Fast neutron spectrum unfolding of a TRIGA Mark II reactor and measurement of spectrum-averaged cross sections: integral tests of differential cross sections of neutron threshold reactions
}

\author{
By M. S. Uddin' ${ }^{1, *}$, S. Sudár ${ }^{2}$, S. M. Hossain ${ }^{1}$, R. Khan ${ }^{1}$, M. A. Zulquarnain ${ }^{3}$ and S. M. Qaim ${ }^{4}$ \\ ${ }^{1}$ Institute of Nuclear Science and Technology (INST), Atomic Energy Research Establishment, Savar, GPO Box-3787, Dhaka-1000, Bangladesh \\ 2 Institute of Experimental Physics, Debrecen University, H-4001 Debrecen, Hungary \\ ${ }^{3}$ Bangladesh Atomic Energy Commission, Dhaka, Bangladesh \\ ${ }^{4}$ Institut für Neurowissenschaften und Medizin, INM-5: Nuklearchemie, Forschungszentrum Jülich, D-52425 Jülich, Germany
}

(Received January 6, 2013; accepted in revised form March 25, 2013)

(Published online October 7, 2013)

TRIGA Mark II reactor / Fast neutron spectrum / Nuclear reaction / Spectrum-averaged cross section / Integral test of differential data

\begin{abstract}
Summary. The spectrum of fast neutrons having energies from 0.5 to $20 \mathrm{MeV}$ in the core of the $3 \mathrm{MW}$ TRIGA Mark II reactor at Savar, Dhaka, Bangladesh, was unfolded by activating several metal foils to induce threshold nuclear reactions covering the whole spectrum, and then doing necessary iterative calculations utilizing the activation results and the code SULSA. The analysed shape of the spectrum in the TRIGA core was found to be similar to that of the pure ${ }^{235} \mathrm{U}$-fission spectrum, except for the energies between 0.5 and $1.5 \mathrm{MeV}$, where it was slightly higher than the fission spectrum. Spectrum-averaged cross sections were determined by integral measurements. The integral values measured in this work were compared with the recommended values for a pure fission spectrum as well as with the integrated data deduced from measured and evaluated excitation functions of a few reactions given in some data files. The good agreement between integral measurements and integrated data in case of well-investigated reactions shows that the fast neutron field at the TRIGA Mark II reactor can be used for validation of evaluated data of neutron threshold reactions.
\end{abstract}

\section{Introduction}

Among the various types of nuclear research reactors operating today, the TRIGA reactors (developed by General Atomics, San Diego, California, USA) occupy a special place because of their enhanced inherent safety and provision for high thermal neutron fluxes. A 3 MW TRIGA Mark II reactor was installed at the campus of Atomic Energy Research Establishment (AERE) of Bangladesh Atomic Energy Commission (BAEC) in Savar in 1986 [cf. 1,2]. It is a zirconium hydride moderated, light-water cooled and graphite (with Al cladding) reflected pulsing type reactor, designed for steady state operation at a thermal power of up

\footnotetext{
*Author for correspondence

(E-mail: md.shuzauddin@yahoo.com).
}

to $3 \mathrm{MW}$ under forced convection cooling. The construction is thus somewhat similar to other TRIGA reactors $[c f .3,4]$ but the maximum achievable power at the Savar reactor is higher. The TRIGA core at Savar consists of 93 LEU fuel elements arranged in a concentric hexagonal array within the core shroud. The fuel is a solid, homogeneous mixture of Er-U-ZrH alloy containing $20 \mathrm{wt}$ \% of uranium (enriched to $\left.19.7 \%{ }^{235} \mathrm{U}\right), 79.53$ wt. \% of $\mathrm{ZrH}_{1.6}$ and about 0.47 wt. \% of erbium.

The reactor has been used till now for medical radioisotope production and nuclear researches in the areas of neutron activation analysis, neutron scattering, neutron radiography etc. For all those areas of activity purely thermal neutron fluxes are preferable. Thermal fluxes are enhanced by built-in graphite reflector plate that surrounds the core. So far research related to fast neutrons has not been performed partly due to a lack of knowledge of fast neutron spectrum available in the reactor core.

For characterization of fast neutron spectra, sophisticated techniques like time of flight, chopper selection, etc. are very beneficial. However, they cannot be used in the vicinity of the reactor core. Presently the characterization is commonly done with advanced Monte Carlo neutron transport computer codes such as MCNP [cf. 4]. However, the computational model in such calculations needs to be verified and validated by experiments which are difficult to carry out. A comparatively simple method is to perform activation of a set of multiple foils of different metals, thereby inducing nuclear reactions with different thresholds, and to use an iterative code to unfold the neutron spectrum. For this purpose, initially codes like SAND II $[c f .5,6]$, CRYSTAL BALL [7], STAY'SL [8], etc. were successfully used, with the condition that a good input spectrum information was available [9]. In particular, the code SAND II was extensively applied to characterize of fast spectral part of fission neutrons $[c f .9,10]$, the spectral shape of quasi-monoenergetic $d-d$ neutrons [11] as well as of $d(\mathrm{Be})$ breakup neutrons [12]. A combined form of SAND II and STAY'SL was used to characterize $d(\mathrm{Be})$ breakup neutrons generated by intermediate energy deuterons $[13,14]$. 
In later years those codes have been further improved. In addition, a new unfolding code, namely SULSA, has been developed [15]. It is also an iterative code which is based on the generalized least squares method (LSQ). The SULSA has two calculational modes: a) unfolding without input spectrum with successive approximation, b) iterative LSQ method with input spectrum. In this work the mode b) was used. To date it has been successfully utilized in unfolding various types of spectra, e.g. the $d(\mathrm{Be})$ breakup neutron spectrum [16-19] and the spectrum originating from an Am/Be radionuclidic source [20,21].

Based on our previous experience, the present work was undertaken to characterize the fast neutron spectrum at the core of the TRIGA Mark II reactor at Savar, Dhaka, Bangladesh, using the above mentioned foil activation in combination with the unfolding code SULSA. Since the shape and intensity of the neutron spectrum are strongly dependent on the irradiation position, it is absolutely necessary to know the exact location near the core of the reactor where the samples are to be irradiated. A well-defined position known as Dry Central Thimble (DCT), is available at the Savar reactor $[1,2]$, and it was used in the present work. We would like to mention that we did not attempt to analyse the low energy part of the neutron spectrum which is very demanding, especially in the case of a TRIGA reactor. Our effort was devoted to the energy region above $0.5 \mathrm{MeV}$ which is interesting for practical applications, such as production of special radionuclides using $(n, p)$ and $(n, \alpha)$ reactions, integral tests of excitation functions of some neutron threshold reactions, etc. Studies on production of ${ }^{64} \mathrm{Cu}$ and ${ }^{67} \mathrm{Cu}$ via the ${ }^{64} \mathrm{Zn}(n, p){ }^{64} \mathrm{Cu}$ and ${ }^{67} \mathrm{Zn}(n, p){ }^{67} \mathrm{Cu}$ reactions have been initiated. In this work, however, we report on our experience related to integral measurements of spectrum-averaged cross sections.

Experimental neutron induced reaction cross section data over a wide energy range up to $20 \mathrm{MeV}$ have been compiled ( $c f$. EXFOR, 2007) [22]. Furthermore, several standardized activation data files have been established or improved. Data testing and validation by integral measurements thus appears to be timely and useful. Therefore, an interesting area of application of neutron fields consists of performing integral tests of excitation functions of neutron induced reactions. In general, such tests are performed using fission neutrons produced in thermal neutron induced fission of ${ }^{235} \mathrm{U}$ or spontaneous fission of ${ }^{252} \mathrm{Cf}$. The maximum in those neutron spectra occurs at $0.8-2 \mathrm{MeV}$, followed by a continuously decreasing intensity up to $20 \mathrm{MeV}$. Some tests using $d(\mathrm{Be})$ breakup neutrons $[17,19]$ as well as Am/Be source neutrons [20,21], with harder neutron energy components, have also been performed. The major aim of the present work was to measure cross sections of a few threshold reactions averaged over the spectrum of the TRIGA reactor (determined in this work) and to compare the results with data reported for a pure fission neutron spectrum. Furthermore, testing of data files utilizing the TRIGA reactor neutron spectrum was also aimed at. As far as we know, spectrum-averaged cross section measurements and data testing using a TRIGA reactor have hitherto not been reported.

\section{Experimental techniques}

\subsection{Samples and irradiations}

High purity foils of several metals, namely $\mathrm{Al}, \mathrm{Ti}, \mathrm{Fe}, \mathrm{Ni}$, $\mathrm{Nb}, \mathrm{Mo}$, In and $\mathrm{Au}$, were cut in circular discs with diameter of $1 \mathrm{~cm}$ and placed in an Al-container, and finally in an irradiation vial. All foils in a stack were irradiated together in the reactor with neutrons at the dry central thimble (DCT), (on stopper plate) which is about $5 \mathrm{~cm}$ below the core centre, where the fast neutron flux is maximum. Fig. 1a shows the cross-sectional view of the core configuration of the TRIGA Mark II reactor. The exact irradiation sample position at DCT in the core is shown in Fig. 1b. The typical irradiation time was $40 \mathrm{~min}$, and during irradiation the reactor power was kept constant at $1 \mathrm{MW}$. A short $10 \mathrm{~min}$ irradiation of In and Au foils was performed in the reactor core at the same power. The details on the irradiation foils and the investigated activation products are given in Table 1.

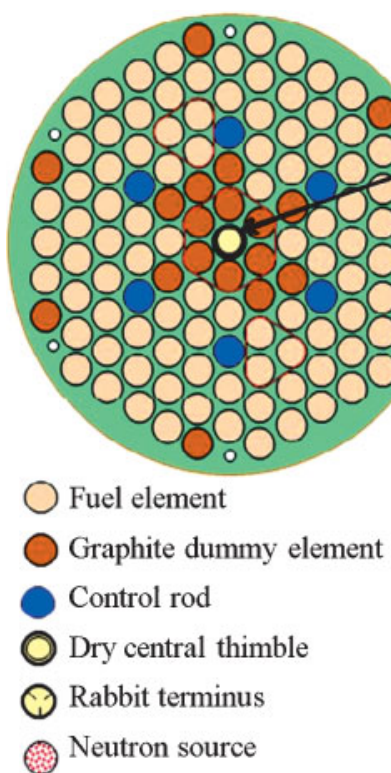

(a)

\section{Reactor top}

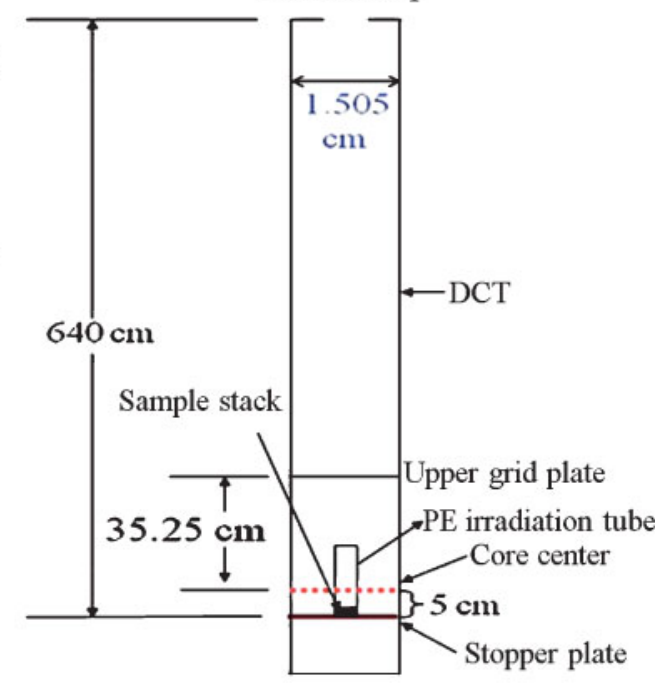

(b)
Fig. 1. Schematic representation of the TRIGA Mark II reactor at Savar; (a) cross-sectional view of reactor core configuration, and (b) exact irradiation sample position (at DCT) in the reactor core. 
Table 1. Irradiated foils and investigated activation products.

\begin{tabular}{|c|c|c|c|c|c|c|c|c|}
\hline \multirow{2}{*}{$\begin{array}{l}\text { Sample } \\
\text { (foil) }\end{array}$} & \multirow{2}{*}{$\begin{array}{l}\text { Purity } \\
\text { (supplier) }\end{array}$} & \multirow{2}{*}{$\begin{array}{l}\text { Nuclear } \\
\text { reaction }\end{array}$} & \multirow{2}{*}{$\begin{array}{l}Q \text {-value } \\
(\mathrm{MeV})\end{array}$} & \multirow{2}{*}{$\begin{array}{c}\text { Threshold } \\
\text { energy }(\mathrm{MeV})\end{array}$} & \multirow{2}{*}{$\begin{array}{c}\text { Reaction } \\
\text { threshold }(\mathrm{MeV})\end{array}$} & \multicolumn{3}{|c|}{ Decay data of the activation product ${ }^{a}$} \\
\hline & & & & & & $T_{1 / 2}$ & $E_{\gamma}(\mathrm{keV})$ & $I_{\gamma}(\%)$ \\
\hline $\mathrm{Al}$ & $\begin{array}{l}99.9 \% \\
\text { (Goodfellow) }\end{array}$ & $\left.{ }^{27} \mathrm{Al}(n, \alpha)\right)^{24} \mathrm{Na}$ & -3.13 & 4.6 & 6.2 & $14.96 \mathrm{~h}$ & 1368.6 & 100 \\
\hline $\mathrm{Ti}$ & $\begin{array}{l}99.9 \% \\
\text { (Goodfellow) }\end{array}$ & $\begin{array}{l}{ }^{46} \mathrm{Ti}(n, p){ }^{46} \mathrm{Sc} \\
{ }^{47} \mathrm{Ti}(n, p){ }^{47} \mathrm{Sc} \\
{ }^{48} \mathrm{Ti}(n, p){ }^{48} \mathrm{Sc}\end{array}$ & $\begin{array}{r}-1.58 \\
0.18 \\
-3.21\end{array}$ & $\begin{array}{l}1.62 \\
0.0 \\
3.74\end{array}$ & $\begin{array}{l}2.0 \\
1.5 \\
6.2\end{array}$ & $\begin{array}{r}83.82 \mathrm{~d} \\
3.35 \mathrm{~d} \\
1.80 \mathrm{~d}\end{array}$ & $\begin{array}{r}889.0 \\
159.3 \\
983.5 \\
1037.6\end{array}$ & $\begin{array}{c}99.98 \\
68.3 \\
100 \\
97.6\end{array}$ \\
\hline $\mathrm{Fe}$ & $\begin{array}{l}99.5 \% \\
\text { (Goodfellow) }\end{array}$ & $\begin{array}{l}{ }^{54} \mathrm{Fe}(n, p){ }^{54} \mathrm{Mn} \\
{ }^{54} \mathrm{Fe}(n, \alpha){ }^{51} \mathrm{Cr}\end{array}$ & $\begin{array}{l}0.08 \\
0.84\end{array}$ & $\begin{array}{l}0.0 \\
0.0\end{array}$ & $\begin{array}{l}1.7 \\
4.5\end{array}$ & $\begin{array}{r}312.20 \mathrm{~d} \\
27.70 \mathrm{~d}\end{array}$ & $\begin{array}{l}834.9 \\
320.0\end{array}$ & $\begin{array}{l}99.98 \\
10.0\end{array}$ \\
\hline $\mathrm{Ni}$ & $\begin{array}{l}99.98 \% \\
\text { (Chempur) }\end{array}$ & ${ }^{58} \mathrm{Ni}(n, p){ }^{58} \mathrm{Co}$ & 0.40 & 0.0 & 0.5 & $70.86 \mathrm{~d}$ & 811.0 & 99.0 \\
\hline $\mathrm{Nb}$ & $\begin{array}{l}99.9 \% \\
\text { (Goodfellow) }\end{array}$ & ${ }^{93} \mathrm{Nb}(n, 2 n)^{92 \mathrm{~m}} \mathrm{Nb}$ & -8.83 & 9.6 & 9.6 & $10.15 \mathrm{~d}$ & 934.5 & 99.0 \\
\hline Мo & $\begin{array}{l}99.9 \% \\
\text { (Goodfellow) }\end{array}$ & $\begin{array}{l}{ }^{92} \mathrm{Mo}(n, p)^{92 \mathrm{~m}} \mathrm{Nb} \\
{ }^{95} \mathrm{Mo}(n, p)^{95} \mathrm{Nb} \\
98 \mathrm{Mo}(n, \alpha)^{95} \mathrm{Zr}\end{array}$ & $\begin{array}{r}0.29 \\
-0.14 \\
3.19\end{array}$ & $\begin{array}{l}0.0 \\
0.16 \\
0\end{array}$ & $\begin{array}{l}2.25 \\
5.0 \\
0.5\end{array}$ & $\begin{array}{l}10.15 \mathrm{~d} \\
34.97 \mathrm{~d} \\
64.02 \mathrm{~d}\end{array}$ & $\begin{array}{l}934.5 \\
765.8 \\
756.7\end{array}$ & $\begin{array}{r}99.0 \\
100 \\
54.0\end{array}$ \\
\hline In & $\begin{array}{l}99.9 \% \\
\text { (Goodfellow) }\end{array}$ & $\begin{array}{l}{ }^{115} \operatorname{In}\left(n, n^{\prime} \gamma\right)^{115 \mathrm{~m}} \mathrm{In} \\
{ }^{113} \operatorname{In}\left(n, n^{\prime} \gamma\right)^{113 \mathrm{~m}} \mathrm{In}\end{array}$ & $\begin{array}{r}0.34 \\
-3.91\end{array}$ & $\begin{array}{l}0.37 \\
0.39\end{array}$ & $\begin{array}{l}0.37 \\
0.39\end{array}$ & $\begin{array}{l}4.49 \mathrm{~h} \\
1.658 \mathrm{~h}\end{array}$ & $\begin{array}{l}336.2 \\
391.69\end{array}$ & $\begin{array}{l}45.83 \\
64.2\end{array}$ \\
\hline $\mathrm{Au}$ & $\begin{array}{l}99.9 \% \\
\text { (Goodfellow) }\end{array}$ & $\left.{ }^{197} \mathrm{Au}(n, \gamma)\right)^{198} \mathrm{Au}$ & 6.51 & 0.0 & 0.0 & $2.69 \mathrm{~d}$ & 411.8 & 96.0 \\
\hline
\end{tabular}

a: Taken from NUDAT database [23].

The decay data were taken from the NUDAT database (National Nuclear Data Center, BNL, USA) [23].

\subsection{Gamma ray spectrometric measurements}

The radioactivity induced in each irradiated foil was measured non-destructively using a high-purity germanium (HPGe) gamma-ray detector associated with a digital gamma spectrometry system (ORTEC DSPEC $\mathrm{jr}^{\mathrm{TM}}$ ) and Maestro data acquisition software. The samples were counted several times over a period of a few months to check the half-lives of the activation products. All the samples were counted at $20 \mathrm{~cm}$ from the detector surface, where the sample-size effect on the efficiency is negligible. At that counting position, the probability of coincidence pulse being detected and summed in the detector system is also expected to be negligible. Due to the sample-detector distance and the solid angle subtended by the sample, the random coincidence loss also became negligible. The gamma-ray spectrum was analysed by GammaVision software. The spectrum was also analysed using the program Hypermet PC 5.12 and compared with that by GammaVision. The efficiency vs. energy curve of the HPGe gamma-ray detector was determined using standard point sources ${ }^{57} \mathrm{Co},{ }^{60} \mathrm{Co},{ }^{133} \mathrm{Ba}$ and ${ }^{152} \mathrm{Eu}$ (supplied by North American Scientific). The count rate of each product radionuclide was extrapolated to the end of bombardment and it was converted to decay rate by applying the usual corrections, like the intensity of the $\gamma$-ray used, the efficiency of the detector, etc. Due to strong contribution of thermal neutrons the background level in the $\gamma$-ray spectrum was rather high, and so the peaks corresponding to the radionuclides ${ }^{115 \mathrm{~m}} \mathrm{In}$ and ${ }^{196} \mathrm{Au}$ formed in In and $\mathrm{Au}$ foils by fast neutrons via the ${ }^{115} \operatorname{In}\left(n, n^{\prime} \gamma\right)^{115 \mathrm{~m}} \mathrm{In}$ and ${ }^{197} \mathrm{Au}(n, 2 n){ }^{196} \mathrm{Au}$ reactions, respectively, could not be detected in the long irradiation. The activity of the former reaction product was determined in the short irradiation.

\section{Data analysis}

\subsection{Neutron spectrum unfolding}

The saturation activity of a reaction product, A, is obtained from the following Eq. (1),

$$
A=N \sigma \Phi
$$

where $N$ is the number of atoms of the particular target isotope, $\sigma$ is the cross section and $\Phi$ is the neutron fluence rate $\left(n \mathrm{~cm}^{-2} \mathrm{~s}^{-1}\right)$. The Eq. (1) can be written in discrete form as Eq. (2),

$$
A_{\mathrm{s} k}=\sum \sigma_{k i} \Phi_{i}
$$

where $A_{\mathrm{s} k}$ is the detected specific saturation activity per atom of the isotope (i.e. $A_{\mathrm{s} k}=A / N$ ) for the activation reaction $k_{i}, \sigma_{k i}$ is the corresponding activation excitation function and $\Phi_{i}$ the neutron spectrum content in energy bin $i$. From the Eq. (2) the neutron fluence spectrum $\Phi$ can be determined. When $k \ll i$, the set of equations is under-determined but they can be solved by applying an unfolding technique.

The activities of the 13 positively identified threshold reactions, covering the full energy range from threshold to $20 \mathrm{MeV}$, are given in Table 1 . They served as the basic data for the calculation. They were given as inputs in the iterative code SULSA [15] for unfolding. The excitation functions for the first seven reactions were taken from the International Reactor Dosimetry File (IRDF) [24], for the ${ }^{95} \mathrm{Mo}(n, p){ }^{95} \mathrm{Nb}$ and ${ }^{115} \operatorname{In}\left(n, n^{\prime} \gamma\right)^{115 \mathrm{~m}}$ In reactions from the Reference Neutron Activation Library [25], for the ${ }^{93} \mathrm{Nb}(n, 2 n)^{92 \mathrm{~m}} \mathrm{Nb}$ and ${ }^{92} \mathrm{Mo}(n, p){ }^{92 \mathrm{~m}} \mathrm{Nb}$ reactions from detailed experimental measurements done at Jülich/Geel [26-28], and for the remaining two reactions, namely ${ }^{98} \mathrm{Mo}(n, \alpha){ }^{95} \mathrm{Zr}$ and ${ }^{113} \operatorname{In}\left(n, n^{\prime} \gamma\right)^{113 \mathrm{~m}} \mathrm{In}$ from TENDL-2011 [29]. The TRIGA neutron spectrum at Ljubljana as shown in Fig. 2 was used as initial spectrum in our calculations. 


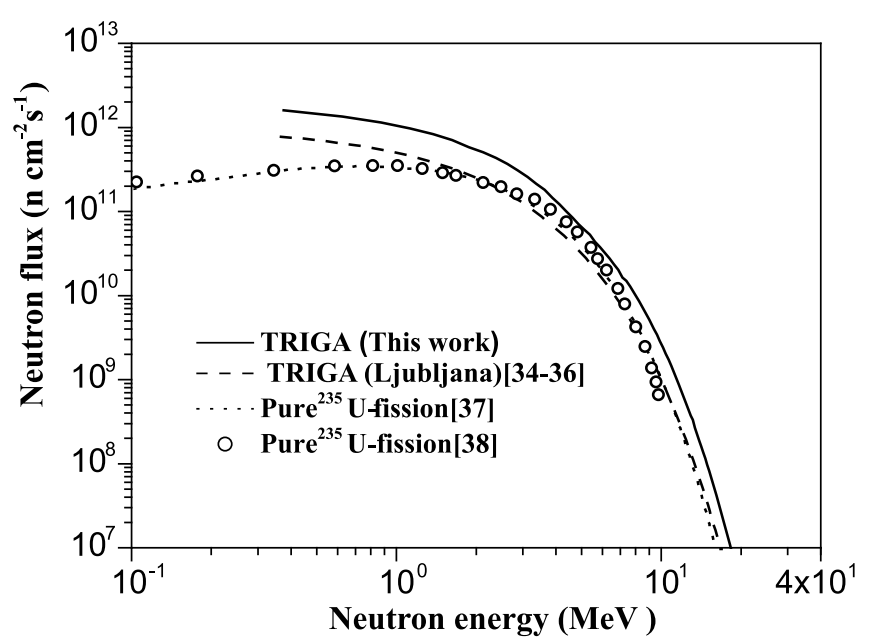

Fig. 2. Unfolded fast neutron spectrum of TRIGA Mark II reactor at Savar at the irradiation position DCT and $1 \mathrm{MW}$ power (this work). For comparison, the spectrum at TRIGA in Ljubljana as well as the pure ${ }^{235} \mathrm{U}$-fission spectrum are also shown.

\subsection{Fast neutron flux}

The ${ }^{58} \mathrm{Ni}(n, p){ }^{58} \mathrm{Co}$ reaction induced in the Ni-monitor foil was used to measure the total fast neutron flux for energies above $0.5 \mathrm{MeV}$. At first the cross section value averaged for the unfolded spectrum (see above) was calculated, which amounted to $91.2 \pm 5.5 \mathrm{mb}$. That value was then used for fast flux calculation. This reaction was chosen since it is available in all data files and there are no significant discrepancies among the excitation functions given in those files. Furthermore, it has a rather low reaction threshold $(0.5 \mathrm{MeV})$, combined with suitable decay properties of ${ }^{58} \mathrm{Co}$ and high production cross section.

\subsection{Thermal neutron flux}

The thermal neutron flux at DCT was determined using the ${ }^{197} \mathrm{Au}(n, \gamma){ }^{198} \mathrm{Au}$ reaction as monitor. The cadmium-ratio foil activation technique was used. The method involved irradiations of bare gold foils and of foils covered with $1 \mathrm{~mm}$ thick separate cadmium sheet. The difference of the two values gave the ${ }^{198} \mathrm{Au}$ activity due to thermal flux. From this activity the thermal neutron flux was determined using the well known formula.

\subsection{Integral measurements of reaction cross sections}

The spectrum-averaged cross sections $\langle\sigma\rangle$ of the reactions $\left.{ }^{27} \mathrm{Al}(n, \alpha)\right)^{24} \mathrm{Na},{ }^{46} \mathrm{Ti}(n, p){ }^{46} \mathrm{Sc},{ }^{47} \mathrm{Ti}(n, p){ }^{47} \mathrm{Sc},{ }^{48} \mathrm{Ti}(n, p)$ ${ }^{48} \mathrm{Sc},{ }^{54} \mathrm{Fe}(n, p){ }^{54} \mathrm{Mn},{ }^{54} \mathrm{Fe}(n, \alpha){ }^{51} \mathrm{Cr},{ }^{92} \mathrm{Mo}(n, p){ }^{92 \mathrm{~m}} \mathrm{Nb}$, $\left.{ }^{93} \mathrm{Nb}(n, 2 n){ }^{92 \mathrm{~m}} \mathrm{Nb} \quad{ }^{95} \mathrm{Mo}(n, p)\right)^{95} \mathrm{Nb},{ }^{98} \mathrm{Mo}(n, \alpha){ }^{95} \mathrm{Zr},{ }^{113} \mathrm{In}$ $\left(n, n^{\prime} \gamma\right)^{113 \mathrm{~m}}$ In and ${ }^{115} \operatorname{In}\left(n, n^{\prime} \gamma\right)^{115 \mathrm{~m}}$ In were determined from the measured decay rates of the activation products at end of bombardment and the neutron flux $(>0.5 \mathrm{MeV})$ effective at the samples, which was determined via the ${ }^{58} \mathrm{Ni}(n, p){ }^{58} \mathrm{Co}$ monitor reaction.

The uncertainties involved in the determination of the cross section are given in Table 2 . The overall uncertainty in the cross section was obtained by summing all the individual uncertainties in quadrature. The overall uncertainties were in the range of $7-9 \%$.
Table 2. Sources of uncertainties in the measured integral cross sections.

Source of uncertainty Uncertainty (\%)

A. Measurement of radioactivity

Peak area analysis

Counting statistics

Efficiency of detector

Half-life of product

$\gamma$-ray intensity

$1-3$

.1-3

5

$<0.1$

$<0.2$

B. Calculation of cross section

Sample mass

0.01

Monitor cross section

6

Total

7-9

\subsection{Integrated reaction cross sections}

The neutron spectrum averaged cross section $\langle\sigma\rangle$ was also calculated using the relation

$$
\langle\sigma\rangle=\int_{E_{\mathrm{thr}}}^{E_{\max }} \sigma\langle E\rangle \phi(E) \mathrm{d} E / \int_{E_{\mathrm{thr}}}^{E_{\max }} \phi(E) \mathrm{d} E
$$

where $\phi(E)$ is the neutron flux at energy $E, E_{\mathrm{thr}}$ is the reaction threshold and $E_{\max }$ is the maximum energy of the neutron in the spectrum, respectively.

The spectrum-averaged integrated cross sections of the above mentioned 12 threshold reactions were obtained using excitation functions reported in the literature [24-33] and the unfolded neutron spectrum above $0.5 \mathrm{MeV}$ determined in this work. Based on the uncertainties in the neutron spectrum and the excitation function, the overall uncertainty in the integrated reaction cross section was estimated to be about $6 \%$.

\section{Results and discussion}

\subsection{Characterization of the TRIGA reactor fast neutron spectrum}

\subsubsection{Spectrum unfolding}

The unfolded neutron spectrum over the energy range of $0.5 \mathrm{MeV}$ to $20 \mathrm{MeV}$ at the DCT of TRIGA Mark II reactor for $1 \mathrm{MW}$ power is shown in Fig. 2. We ascribe an uncertainty of about $6 \%$ to the various regions of the spectrum. The achieved chi- 2 value was 0.87 which is a good measure of how well the spectrum is unfolded [ $c f .39]$. For comparison, the spectrum analysed at the TRIGA Mark II reactor in Ljubljana [34-36] is also shown. The Ljubljana reactor has the same fuel enrichment and cladding as the Savar reactor, but operates at a lower power of up to $250 \mathrm{~kW}$. The data shown in Fig. 2 were normalized to a power of $1 \mathrm{MW}$. Although the fast neutron spectrum at the Ljubljana reactor was unfolded using another code (an updated 1994 version of SAND II) and four $(n, \gamma)$ and four neutron threshold reactions, namely ${ }^{115} \mathrm{In}\left(n, n^{\prime} \gamma\right)^{115 \mathrm{~m}} \mathrm{In},{ }^{27} \mathrm{Al}(n, \alpha){ }^{24} \mathrm{Na}$, ${ }^{59} \mathrm{Co}(n, p){ }^{59} \mathrm{Fe}$ and ${ }^{59} \mathrm{Co}(n, \alpha){ }^{56} \mathrm{Mn}$, the agreement between that spectrum and our spectrum in shape is good. The small difference in magnitude is possibly due to the normalization process. 
It appears instructive to compare the fast neutron spectrum of a TRIGA reactor determined in this work and at Ljubljana with the high-energy part of a pure ${ }^{235} \mathrm{U}$-fission spectrum $[c f .37,38]$, also shown in Fig. 2 after normalization to a power of $1 \mathrm{MW}$. Whereas the energy region above $1 \mathrm{MeV}$ coincides well with the TRIGA reactor spectrum, in the energy range below $1.0 \mathrm{MeV}$, there is considerable deviation. Worth pointing out here is the result of a spectrum unfolding study at a swimming pool type research reactor at PINSTECH in Pakistan [10] which, at the time of experiment, utilized about $93 \%$ enriched ${ }^{235} \mathrm{U}$ as fuel and was operated at a thermal power up to $5 \mathrm{MW}$. The fast neutron spectrum of the PINSTECH reactor was found to be very similar to that for pure ${ }^{235} \mathrm{U}$ fission. All those results suggest that the TRIGA spectrum is somewhat higher in the energy region between 0.5 and $1.5 \mathrm{MeV}$ than the pure ${ }^{235} \mathrm{U}$-fission spectrum. There could be several reasons, e.g. difference in fuel cladding, presence of $\mathrm{ZrH}_{1.6}$, lower enrichment of ${ }^{235} \mathrm{U}$ in TRIGA (i.e. higher concentration of ${ }^{238} \mathrm{U}$ ), presence of a thick graphite plate in the vicinity of the core, which thermalises and reflects neutrons, etc.

\subsubsection{Lethargy plot for the TRIGA spectrum}

The neutrons are born with energies corresponding to the fast energy region. They interact with the surrounding nuclei and due to collisions their energy is reduced. Some of those neutrons produce fission as they are slowed down, but in a thermal reactor it happens with a rather low probability. In a thermal reactor, the total number of neutrons generated in fission divided by the number of neutrons produced by the thermal fission slightly exceeds unity. In the upper energy region where the slowing-down is the main process and no significant number of neutrons emerge from fission, it is convenient to introduce a variable called lethargy, related to energy. The lethargy plot of the unfolded spectrum is shown in Fig. 3. The mean energy of the unfolded spectrum is $1.625 \mathrm{MeV}$. A comparable value of $1.73 \mathrm{MeV}$ was reported for the Ljubljana reactor spectrum [36].

\subsection{Neutron fluxes}

Using the ${ }^{58} \mathrm{Ni}(n, p){ }^{58} \mathrm{Co}$ reaction as monitor the flux of neutrons above $0.5 \mathrm{MeV}$ was determined to be about $9.98 \times 10^{12} n \mathrm{~cm}^{-2} \mathrm{~s}^{-1}$ at the reactor power of $1 \mathrm{MW}$. The flux of thermal neutrons via the ${ }^{197} \mathrm{Au}(n, \gamma){ }^{198} \mathrm{Au}$ reaction amounted to $2.48 \times 10^{13} n \mathrm{~cm}^{-2} \mathrm{~s}^{-1}$. Huda et al. [2] reported a flux pattern calculated by MCNP within the DCT of the same reactor. By adopting the total fast neutrons of Huda et al. [2] and our measured value above $0.5 \mathrm{MeV}$, the neutron flux between epithermal and $0.5 \mathrm{MeV}$ is estimated to be $4.69 \times 10^{12} n \mathrm{~cm}^{-2} \mathrm{~s}^{-1}$. Thus the fast neutrons amount to $36 \%$ (11\% are from epithermal to $0.5 \mathrm{MeV}$ and $25 \%$ from 0.5 to $20 \mathrm{MeV}$ ) of the total number of neutrons.

\subsection{Spectrum-averaged cross sections}

The experimentally determined integral cross sections, averaged over the fast neutron spectrum $\left(E_{n}>0.5 \mathrm{MeV}\right)$, are given in Table 3 . The total uncertainty of each value amounts

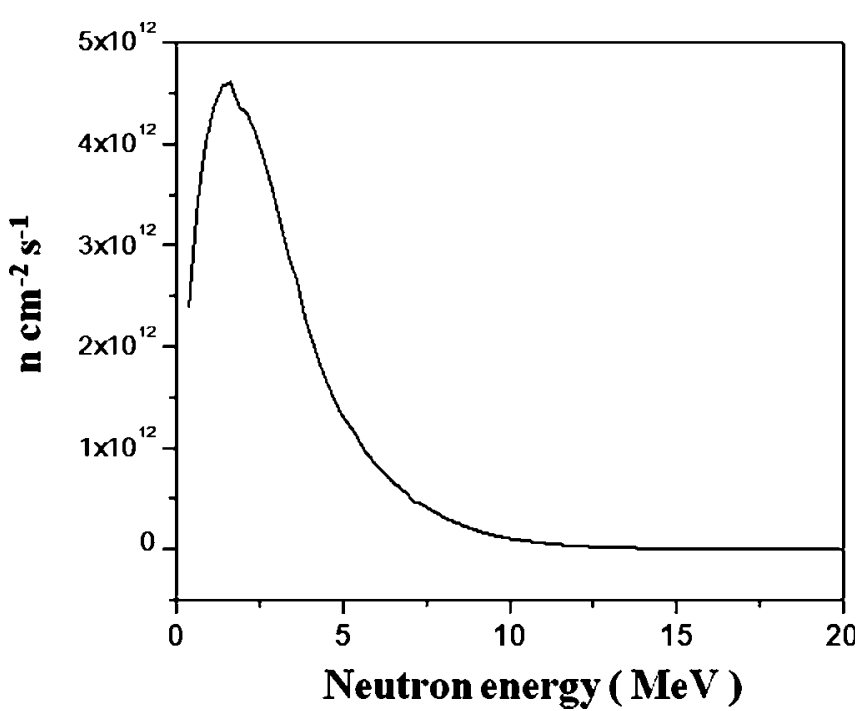

Fig. 3. Lethargy plot of the unfolded spectrum of TRIGA Mark II reactor at Savar. The mean energy of the unfolded spectrum was found to be $1.625 \mathrm{MeV}$.

to about $9 \%$. The integrated spectrum-averaged cross sections calculated from the experimental or evaluated excitation curves are also given in Table 3 .

\subsubsection{Comparison of the measured integral data with the recommended values for the pure fission spectrum}

A comparison of our measured integral data with the normalized and recommended values for the pure fission spectrum ( $c f$. Calamand, [40]) was done. Our measured integral values are generally somewhat lower than the Calamand recommended values (within $8-15 \%$ ). This is interpreted to be due to the difference between the TRIGA neutron spectrum and the pure fission spectrum below about $1.5 \mathrm{MeV}$.

For the two reactions, namely ${ }^{95} \mathrm{Mo}(n, p){ }^{95} \mathrm{Nb}$ and ${ }^{54} \mathrm{Fe}(n, \alpha){ }^{51} \mathrm{Cr}$, however, the integral values measured in this work are higher than those recommended by Calamand [40]. On the other hand, the recommended value of $0.143 \mathrm{mb}$ for the ${ }^{95} \mathrm{Mo}(n, p){ }^{95} \mathrm{Nb}$ reaction was estimated from the weighted average of only two renormalized values, 0.15 and $0.137 \mathrm{mb}$. Similarly, two renormalized values 0.85 and $0.6 \mathrm{mb}$ for the ${ }^{54} \mathrm{Fe}(n, \alpha){ }^{51} \mathrm{Cr}$ reaction are available but the latter was selected for recommendation. Thus, our measured integral values for those two reactions may help to get proper recommended values for the pure fission spectrum.

\subsubsection{Comparison of the measured integral data with evaluated data files and literature}

The spectrum-integrated cross sections from the known excitation functions (given in evaluated data files and literature, see above) were compared with our measured integral cross sections. The ratio of calculated/measured integral cross section for each reaction is given in Table 3 .

For ten reactions, namely ${ }^{27} \mathrm{Al}(n, \alpha){ }^{24} \mathrm{Na},{ }^{46} \mathrm{Ti}(n, p){ }^{46} \mathrm{Sc}$, ${ }^{47} \mathrm{Ti}(n, p){ }^{47} \mathrm{Sc},{ }^{48} \mathrm{Ti}(n, p){ }^{48} \mathrm{Sc},{ }^{54} \mathrm{Fe}(n, p){ }^{54} \mathrm{Mn},{ }^{54} \mathrm{Fe}(n, \alpha)$ ${ }^{51} \mathrm{Cr},{ }^{98} \mathrm{Mo}(n, \alpha){ }^{95} \mathrm{Zr},{ }^{93} \mathrm{Nb}(n, 2 n){ }^{92 \mathrm{~m}} \mathrm{Nb},{ }^{113} \mathrm{In}\left(n, n^{\prime} \gamma\right){ }^{113 \mathrm{~m}} \mathrm{In}$ and ${ }^{115} \operatorname{In}\left(n, n^{\prime} \gamma\right)^{115 \mathrm{~m}} \mathrm{In}$, the $\langle\sigma\rangle_{\text {cal }} /\langle\sigma\rangle_{\text {meas }}$ ratio for most of the files lies between 0.90 and 1.07, showing that the agreement between the integrated data and the integrally measured data is within $\pm 6 \%$, except for two cases where it is within 


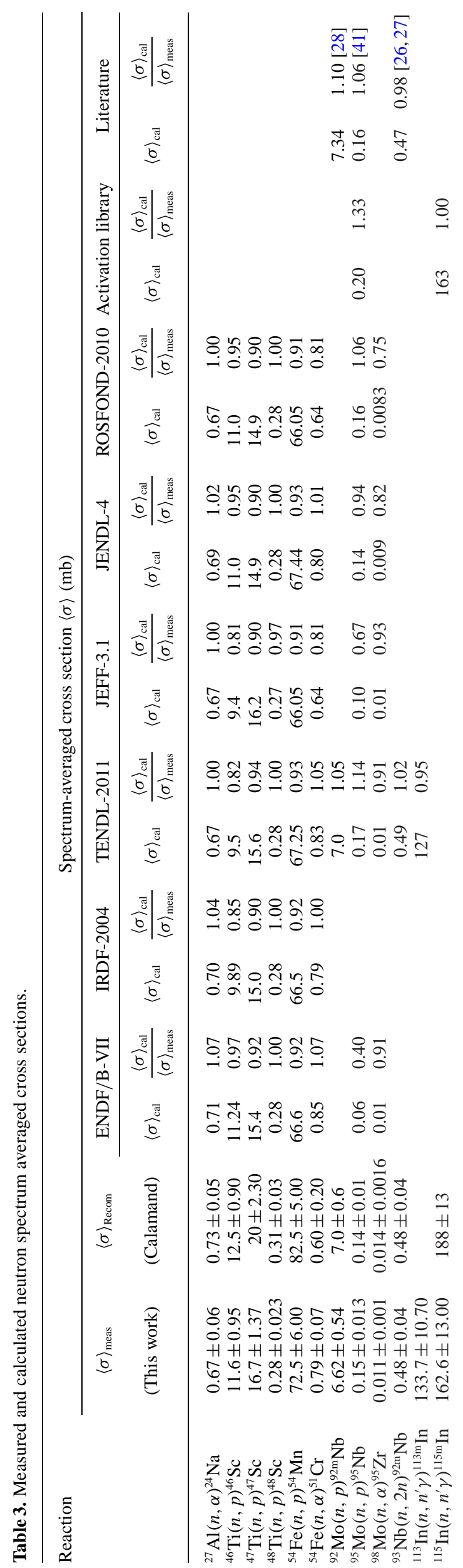

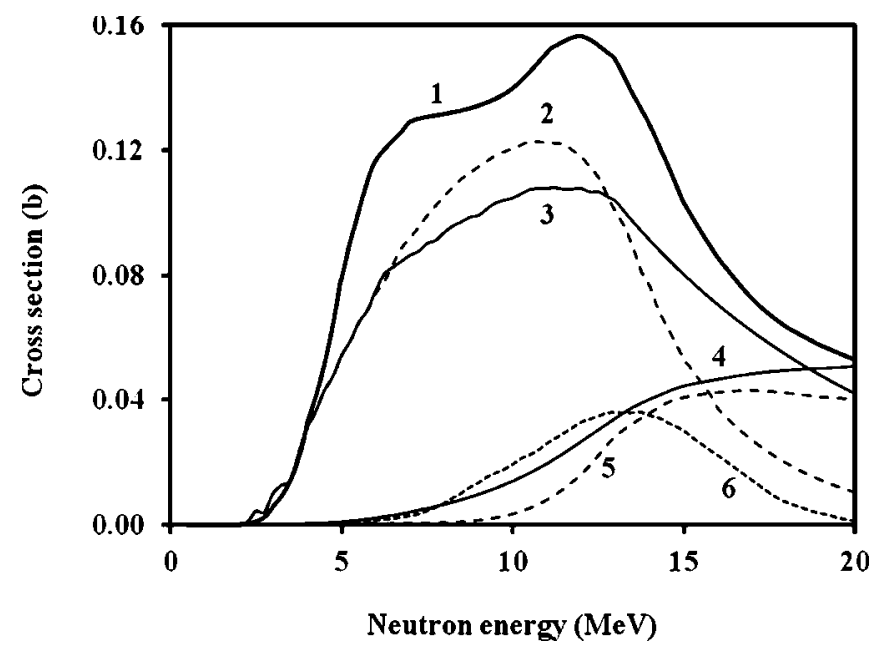

Fig. 4. Excitation functions of the ${ }^{92} \mathrm{Mo}(n, p){ }^{92 \mathrm{~m}} \mathrm{Nb}$ and ${ }^{95} \mathrm{Mo}(n, p)$ ${ }^{95} \mathrm{Nb}$ reactions. Curves: $1 .{ }^{92} \mathrm{Mo}(n, p){ }^{92} \mathrm{Nb}$, ENDF/B-VII; $2 .{ }^{92} \mathrm{Mo}$ $(n, p)^{92 \mathrm{~m}} \mathrm{Nb}$, TENDL-2011; 3. ${ }^{92} \mathrm{Mo}(n, p)^{92 \mathrm{~m}} \mathrm{Nb}$, experimental trend [Ref.28]; 4. ${ }^{95} \mathrm{Mo}(n, p){ }^{95} \mathrm{Nb}$, TENDL-2011; 5. ${ }^{95} \mathrm{Mo}(n, p){ }^{95} \mathrm{Nb}$, ENDF/B-VII; 6. ${ }^{95} \mathrm{Mo}(n, p){ }^{95} \mathrm{Nb}$, experimental trend [41]. The curve for this reaction given in JENDL-4 and ROSFOND-2010 is similar to that in Ref. [41] whereas that in JEF-3.1 and Activation Library it is somewhat similar to that in ENDF/B-VII.

10\%. A few files show larger deviation. In general, however, the good agreement reflects the status of the excitation functions of the ten reactions considered. Since they have been experimentally well investigated ( $c f$. EXFOR [22]), the evaluations are reliable. The two reactions where some discrepancies have been observed are discussed below.

With regard to the reaction ${ }^{95} \mathrm{Mo}(n, p){ }^{95} \mathrm{Nb}$, the $\langle\sigma\rangle_{\text {cal }} /$ $\langle\sigma\rangle_{\text {meas }}$ for the ENDF/B-VII is very far from 1.0. It should be pointed out that this reaction has not been so extensively investigated as the reactions discussed above (cf. Fig. 4). In the critical energy range of 4 to $10 \mathrm{MeV}$, for example, only measurements by Rahman and Qaim [41] are available. Thus, in some evaluations, reliance is more on nuclear model calculations rather than on experimental data. The disagreement between the integral measurement and the calculated results from ENDF/B-VII, JEF-3.1 and Activation Library is possibly due to this reason. The results in case of other files are somewhat more consistent.

No value for the ${ }^{92} \mathrm{Mo}(n, p)^{92 \mathrm{~m}} \mathrm{Nb}$ reaction is reported in ENDF/B-VII and IRDF-2004. The value given in ENDF/BVII possibly refers to the combined formation cross section of the metastable state and the ground state of ${ }^{92} \mathrm{Nb}$. The excitation function given in TENDL-2011, however, describes the formation of ${ }^{92 \mathrm{~m}} \mathrm{Nb}$. Experimentally Qaim et al. [28] reported a reliable excitation function of this reaction. The spectrum-averaged cross sections for this reaction obtained using the excitation functions reported in TENDL-2011 and by Qaim et al. are consistent with the measured integral data.

\section{Conclusions}

The neutron spectrum in the energy range of 0.5 to $20 \mathrm{MeV}$ in the core of the TRIGA Mark II reactor at AERE, Savar, Dhaka, was characterized. The irradiation sample in the core of TRIGA is exposed to a lot of fast neutrons above $0.5 \mathrm{MeV}$. This part of the spectrum could be very beneficial 
for radionuclide development work using $(n, p)$ and $(n, \alpha)$ reactions as well as for integral tests of excitation functions of some neutron threshold reactions given in data files. The latter aspect was studied in detail.

The integrated cross section of a reaction obtained from the unfolded TRIGA spectrum and the known excitation function given in a data file differs by about $10 \%$ from the integrally measured spectrum- averaged value in ten of the investigated cases. The deviations are attributed largely to the statistical error in peak area determination and uncertainty in the excitation function. For two reactions where the quality of the known excitation function is not high, the deviation is larger. In general, however, it is concluded that for well-investigated neutron threshold reactions, the TRIGA Mark II reactor neutron field could be used for validation of evaluated data.

Acknowledgment. We thank Professor H. H. Coenen of Juelich, Germany, for his support of this cooperation, and Dr. I. Spahn and Mr. S. Spellerberg, also at Juelich, for some technical help. The authors thank the operation crew of the TRIGA Mark II nuclear reactor, Savar, Dhaka, for their help in performing irradiations of the samples. M. S. Uddin specially thanks the Alexander von Humboldt Foundation in Germany for financial support to conduct this research work in Bangladesh, and the Radiation Testing and Monitoring Laboratory, Chittagong, for granting him leave of absence to perform the experiments at BAEC facilities at Savar, Dhaka. Some useful information provided by Professor B. Smodis on the Ljubljana reactor is gratefully acknowledged. The authors also express their appreciation to Professor J. Csikai of Debrecen, Hungary, for his support of the nuclear data research programme at Savar in its early phase.

\section{References}

1. Zulquarnain, M. A., Haque, M. M., Salam, M. A., Islam, M. S., Shaha, P. K., Sarder, M. A., Haque, A., Soner, M. A. M., Uddin, M. M., Rahman, M. M., Kamal, I., Islam, M. N., Hossain, S. M.: Experience with operation, maintenance and utilization of the 3 MW TRIGA Mark-II research reactor of Bangladesh. Int. J. Nucl. Ener. Sci. Tech. 4(4), 299-312 (2009).

2. Huda, M. Q., Islam, M. S., Rahman, M. M., Haque, A., Uddin, M.: Studies on the overall safety aspects during irradiation of $\mathrm{TeO}_{2}$ in the central thimble of the TRIGA research reactor. Ann. Nucl. Energ. 36, 199-212 (2009).

3. Hampel, G., Eberhardt, K.: The research reactor TRIGA Mark II of the Johannes Gutenberg-University Mainz. Atomwirtschaft 57, 614-615 (2012).

4. Snoj, L., Zerovnik, G., Trkov, A.: Computational analysis of irradiation facilities at the JSI TRIGA reactor. Appl. Radiat. Isot. 70, 483-488 (2012).

5. McElroy, W. N., Berg, S., Crockett, T., Hawkins, R. G.: A computer automated iterative method for neutron flux spectra determination by foil activation. AFWL-TR-67-41, vol. I, Atomics International (1967).

6. Oster, C. A., McElroy, W. N., Marr, J. M.: A monte carlo program for SAND II error analysis, HEDL-TME 73-20, Handford Engineering Development Laboratory (1973).

7. Kam, F. B. K., Stallmann, F. W.: A computer program for determining neutron spectrum from activation measurement. Report ORNL-TM-4601, Oak Ridge National Laboratory (1974).

8. Perey, F. G.: Least squares dosimetry unfolding: The program STAY'SL, ORNL/TM-6062, Oak Ridge National Laboratory (1977).

9. Zijp, W. L., Baard, J. H., Nolthenius, H. J.: Comparison of neutron spectrum unfolding codes. Proc. $2^{\text {nd }}$ ASTM-EURATOM Symp. On Reactor Dosimetry, Palo Alto, California, 1977, NUREG/CP004, 3, 1365, U.S. Nuclear Regulatory Commission (1977).

10. Mannan, A., Qureshi, I. H., Iqbal, M. Z., Wölfle, R., Qaim, S. M.: Integral tests of differential cross sections for $(n, \alpha)$ and $(n, 2 n)$ reactions on niobium. Radiochim Acta 51, 49-53 (1990).
11. Qaim, S. M., Wölfle, R., Rahman, M. M., Ollig, H.: Measurement of $(n, p)$ and $(n, \alpha)$ reaction cross sections of some isotopes of nickel in the energy region of 5 to $10 \mathrm{MeV}$ using a deuterium gas target at a compact cyclotron. Nucl. Sci. Eng. 88, 143-153 (1984).

12. Wölfle, R., Khatun, S., Qaim, S. M.: Triton emission cross sections with $30 \mathrm{MeV} d(\mathrm{Be})$ break-up neutrons. Nucl. Phys. A $\mathbf{4 2 3}$, 130-138 (1984).

13. Wölfle, R., Sudár, S., Qaim, S. M.: Determination of excitation function of triton emission reaction on aluminium from threshold up to $30 \mathrm{MeV}$ via activation in diverse neutron fields and unfolding code calculations. Nucl. Sci. Eng. 91, 162-172 (1985).

14. Wölfle, R., Suhaimi, A., Qaim, S. M.: Determination of the excitation function of the $(n, x t)$ process on beryllium via activation in diverse neutron fields and unfolding code calculations. Nucl. Sci. Eng. 115, 71-75 (1993).

15. Sudár, S.: A solution for the neutron spectrum unfolding problem without using input spectrum. IAEA-INDC (HUN)-026/L, IAEA, Vienna, Austria (1989).

16. Oláh, L., El-Megrab, A. M., Fenyvesi, A., Majdeddin, A. D., Dóczi, R., Semkova, V., Qaim, S. M., Csikai, J.: Investigations on neutron fields produced in ${ }^{2} \mathrm{H}(d, n){ }^{3} \mathrm{He}$ and ${ }^{9} \mathrm{Be}(d, n){ }^{10} \mathrm{~B}$ reactions. Nucl. Instrum. Methods A 404, 373-380 (1998).

17. Ibn Majah, M., Chiadli, A., Sudár, S., Qaim, S. M.: Cross sections of $(n, p),(n, \alpha)$ and $(n, 2 n)$ reactions on some isotopes of zirconium in the neutron energy range of $10-12 \mathrm{MeV}$ and integral tests of differential cross section data using a $14 \mathrm{MeV} d(\mathrm{Be})$ neutron spectrum. Appl. Radiat. Isot. 54, 655-662 (2001).

18. Spahn, I., Coenen, H. H., Qaim, S. M.: Enhanced production possibility of the therapeutic radionuclides ${ }^{64} \mathrm{Cu},{ }^{67} \mathrm{Cu}$ and ${ }^{89} \mathrm{Sr}$ via $(n, p)$ reactions induced by fast spectral neutrons. Radiochim. Acta 92, 183-186 (2004)

19. Al-Abyad, M., Spahn, I., Sudár, S., Morsy, M., Comsan, M. N. H., Csikai, J., Qaim, S. M., Coenen, H. H.: Nuclear data for production of the therapeutic radionuclides ${ }^{32} \mathrm{P},{ }^{64} \mathrm{Cu},{ }^{67} \mathrm{Cu},{ }^{89} \mathrm{Sr},{ }^{90} \mathrm{Y}$ and ${ }^{153} \mathrm{Sm}$ via the $(n, p)$ reaction: evaluation of excitation function and its validation via integral cross section measurement using a $14 \mathrm{MeV} d(\mathrm{Be})$ neutron source. Appl. Radiat. Isot. 64, 717-724 (2006).

20. Uddin, M. S., Zaman, M. R., Hossain, S. M., Spahn, I., Sudár, S., Qaim, S. M.: An Am/Be neutron source and its use in integral tests of differential neutron reaction cross section data. Appl. Radiat. Isot. 68(9), 1656-1661 (2010).

21. Qaim, S. M., Uddin, M. S., Hossain, S. M., Spahn, I., Zaman, M. R.: Cross section measurements of a few threshold reactions induced by fast neutrons from an Am/Be source: integral tests of differential neutron cross section data. Radiochim. Acta 101, 205-209 (2013).

22. EXFOR, 2007: IAEA Nuclear Data Center, http://www-nds.iaea. org/exfor/exfor.htm, Database Version of 1 September 2009.

23. NUDAT: Decay Radiation Database, http://www.nndc.bnl.gov/ nudat2 (2009).

24. IRDF-2004 (The International Reactor Dosimetry File): IAEA, Vienna (2004).

25. IAEA-TECDOC-1285: Reference Neutron Activation Library. International Atomic Energy Agency, Vienna (2002).

26. Wölfle, R., Mannan, A., Qaim, S. M., Liskien, H., Widera, R.: Excitation functions of ${ }^{93} \mathrm{Nb}(n, 2 n)^{92 \mathrm{~m}} \mathrm{Nb},{ }^{93} \mathrm{Nb}(n, \alpha){ }^{90 \mathrm{~m}, \mathrm{~g}} \mathrm{Y}$, ${ }^{139} \mathrm{La}(n, \alpha){ }^{136} \mathrm{Cs}$ and ${ }^{181} \mathrm{Ta}(n, p){ }^{181} \mathrm{Hf}$ reactions in the energy range of 12.5-19.6 MeV. Appl. Radiat. Isot. 39, 407-412 (1988).

27. Mannan, A., Qaim, S. M.: Activation cross sections and isomeric cross section ratios for the ${ }^{93} \mathrm{Nb}(n, \alpha)^{90 \mathrm{~m}, \mathrm{~g}} \mathrm{Y}$ process. Phys. Rev. C 38, 630-632 (1988).

28. Qaim, S. M., Wölfle, R., Strohmaier, B.: First and second chance proton emission in the interactions of fast reactions with ${ }^{92} \mathrm{Mo}$. Phy. Rev. C 40(5), 1993-1998 (1989).

29. Koning, A. J., Rochman, D.: TENDL-2011, TALYS-based Evaluated Nuclear Data Library, Release date: 29 December 2011, ftp://ftp.nrg.eu/pub/www/talys/tendl2011/tendl2011.html.

30. ENDF/B-VII, 2006: National Nuclear Data Center, Brookhaven National Laboratory, USA, Database version of 15 December 2006.

31. Joint Evaluated Fission and Fusion File, Version 3.1.2, released 2012, JEFF 3.1.2, http://www.oecd-nea.org/dbforms/data/eva/ evatapes/jeff_31/JEFF312.

32. Shibata, K., Iwamoto, O., Nakagawa, T., Iwamoto, N., Ichihara, A., Kunieda, S., Chiba, S., Furutaka, K., Otuka, N., Oh- 
sawa, T., Murata, T., Matsunobu, H., Zukeran, A., Kamada, S., Katakura, J.: JENDL-4.0: a new library for nuclear science and engineering. J. Nucl. Sci. Technol. 48(1), 1 (2011).

33. Russian File of Evaluated Neutron Data, released 2010, ROSFOND-2010, http://www.ippe.ru/podr/abbn/english/libr/rosfond. php.

34. Kristof, E. S.: Characterization of neutron flux in the exposure channel F19 of the Triga Mark II reactor in Ljubljana. Proc. of the Conf. on Nucl. Energy in Central Europe '98, Terme Catez, Slovenia, Nuclear Society of Slovenia (1998), pp. 43-48.

35. Zontar, D.: Study of radiation damage in silicon detectors for high luminosity experiments at LHC. Ph.D. Thesis, University of Ljubljana, Slovenia (1998).

36. Lindstroem, G., Kramberger, G.: TRIGA irradiations-neutron energy spectrum, displacement function and hardness factor, Sirecoils. WODEAN Workshop, University of Hamburg, 17-19 April 2008.
37. Walsh, R. L.: Calculation of fission spectrum integrals for the energy region $15-20 \mathrm{MeV}$ of fission neutron spectra, NEANDC(E) 241/L, INDC (FR) 70/L (1987).

38. Stöcklin, G.: Radionuclides. In: Ullmanns Encyklopädie der technischen Chemie. Verlag Chemie GmbH, Weinheim (1981), vol. 20 , chapt. 3, p. 27.

39. Lövestam, G., Hult, M., Fessler, A., Gasparro, J., Kockerols, P., Okkinga, K., Tagziria, H., Vanhavere, F., Wieslander, J. S. E.: Neutron fluence spectrometry using disk activation. Radiat. Meas. 44, 72-79 (2009)

40. Calamand, A.: Cross sections for fission neutron spectrum induced reactions. In: Handbook on Nuclear Activation Cross Sections. Technical Report No. 156, IAEA, Vienna (1974), p. 273.

41. Rahman, M. M., Qaim, S. M.: Excitation functions of some neutron threshold reactions on isotopes of molybdenum. Nucl. Phys. A 435, 43-53 (1985). 